\title{
Grounds for concern: geotechnical issues from some recent construction cases
}

1 David Tonks PhD, CEng, CGeol, FICE, MAE Technical Director, Coffey Geotechnics, Manchester, UK (corresponding author: david_tonks@coffey.com)
2 Eugene Gallagher CEng, FICE Technical Director, Coffey Geotechnics, Manchester, UK

3 Ian Nettleton Eur Geol, CEng, MIMM, CGeol, FGS Technical Director, Coffey Geotechnics, Manchester, UK
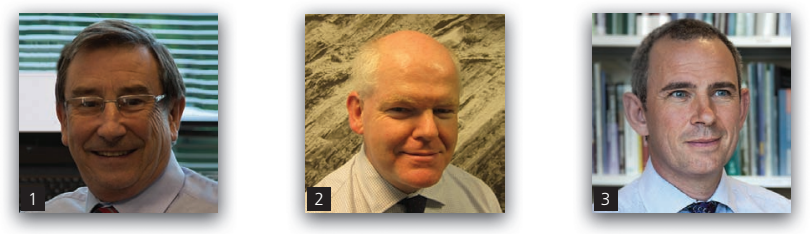

There continue to be many substantial cases of engineering failures associated with the ground, some very problematic and expensive. This is despite most of the technical issues being well known and the subject of much study and comment. Too often for non-specialists, the lessons continue to be learnt only by bitter experience. This paper reviews various issues and risks from the perspective of the authors' practical experiences, mostly acting in expert roles investigating and advising on numerous geotechnical cases related to construction. These involve a wide variety of types of failures and circumstances. They include foundations, shallow and deep; slopes and infrastructure for road, rail and utilities; and mining and waste industries. The examples select some of the more substantial cases, with costs frequently of many millions of pounds. None here involved loss of life, but in several cases, this was fortuitous. Some significant implications and learning points are discussed.

\section{Introduction}

This paper reviews findings from more than 100 geotechnical construction-related cases with which the authors have been directly involved, mostly in an expert capacity in investigation and dispute resolution. Most have involved legal representatives, insurers, clients and asset owners, consultants, contractors and specialist suppliers. Most are in the UK, but a few are international cases. They cover most areas of civil engineering and most types of contractual arrangements. The authors also draw on many other reported cases that they have had reason to study. This paper excludes non-construction cases - for example, natural geohazards - for another paper, but many similar issues and comments arise.

Specific details have been kept appropriately limited and confidential, noting that the roles of parties are often complex and at issue. Aspects are often known only partially to different parties. Opinions are necessarily subjective; the authors would be glad to set the record straight where they might have seen only a part of the picture. They act primarily as consultants and designers in the relevant fields. Their roles in cases described here have been about equally for claimants and defendants and occasionally as single joint experts or other independent roles. Some common themes are discussed, notably failures to interpret the ground adequately. Most of the problems were reasonably avoidable had appropriate existing knowledge been brought to bear at a suitable time. Some recommendations are given for improved identification, reduction, management and communication of risks in the ground.
About half of the cases are categorised as substantial, typically involving claims in excess of $£ 1$ million and sizable damage and delay. About $20 \%$ are termed major, broadly involving costs exceeding $£ 10$ million, in some cases over $£ 100$ million, and major consequences. Related issues are identified as having proportionate consequences, to enable some broad conclusions to be drawn. It is worth adding that some of the smaller cases have been among the most technically interesting and challenging. It is also important to acknowledge the personal aspects where lives may be greatly affected. This ranges from traumatic incidents and events moving at high speed, through managing consequences and finding the best way out', to the relentless grind of legal or other resolution processes.

More than $80 \%$ of the cases involved claims against the designers, and over 50\% involved the main contractor. Around $35 \%$ involved both, often with substantial issues between design and construction, sometimes quite complex and subtle. Some involved several designers or specialists - for example, a lead civil/structural designer, with a geotechnical specialist or supplier. When things go wrong in the ground, a client may not know key facts and may be left to pursue several parties who may contest matters long and hard. He/she often finds himself/herself carrying very substantial risks and disturbance to his/her operations or plans, together with the worries and responsibilities of finding a satisfactory way forward.

In most cases, it was evident that there had been a substantial loss and the issues were essentially who, if anyone, may be liable. 
Most were failures, rather than contractual claims, which tend to be more quantum based, but sometimes involve substantial liability or geotechnical issues. A recent example involved several geotechnical experts arguing the merits of an onerous fill specification, zealously interpreted, expensively and wrongly in the contractor's view. Nothing failed, nor was likely to, but the costs ran into millions of pounds and someone had to pay!

Most of the cases were settled by some form of alternative dispute resolution, with only about $20 \%$ getting to court or other 'forum' with a clear finding of liability. Around $20 \%$ were essentially unsuccessful, including some not pursued for various reasons. It is sometimes an expert's role to advise that a claim is not substantiated or, conversely, that an issue may be technically indefensible. The majority of claimants had a measure of success, but few got everything they asked for. Many cases also incurred substantial costs. Although rarely very transparent, the true costs in time of disruption and disturbance to the parties are often high, sometimes outweighing the sums claimed and making settlement difficult, as cases proceed and costs grow. While project owners naturally want to pass the risks in the ground to others, it is evident that these often 'come back to bite'. Perhaps the most telling issue is reluctance to spend money 'up front' on ground investigations and particularly on interpretation. This appears to have increased in recent years, perhaps particularly where organisations have limited in-house engineering expertise or are not inclined to listen to engineering advisers. This is sometimes said to be 'commercial' or 'cost driven', perhaps ironically where large sums have hung on the absence or shortcomings in investigation or interpretation costing a few thousand pounds. Where a construction contract is let without an adequate site investigation, the client team owns a very substantial risk, which is unlikely to be mitigated fully by any amount of legal manoeuvring, insurance, project management or whatever devices.

\section{Geotechnical hazards and risk management}

Much has been written on geohazards, geotechnical and geological risk management (GeoRM). The interested reader is referred to van Staveren (2006), SISG (2013) and ISSMGE TC304 (2013), which lead to numerous links. The key points here are the following.

- Geotechnical risk should be 'owned' by professionals with appropriate expertise (as should each type of risk identified).

- GeoRM needs to be suitably integrated within project risk management. In practice, this means better integration and incorporation of experienced geotechnical professionals within the project core team.

An example is a major failure a few years ago where a project risk register listed insurance as the relevant mitigation measure against tunnel collapse, but omitted appropriate site observation and monitoring. This should have identified construction procedures that differed significantly from the design approach and then developing movements of the tunnel crown greatly exceeding the design predictions. Appropriate interpretation should have averted the ensuing collapse, which proved enormously costly and, but for fortune, could well have led to major loss of life. There have been other comparable cases that were not so fortunate, avoidable by monitoring and geotechnical expertise on site.

Ground is naturally variable and uncertain, fundamentally different from most other engineering materials and systems, for which quality and behaviours can be defined with great precision and confidence. Variable stresses, histories, groundwater, drainage and environmental conditions can have significant influence. Engineering standards tend to be codified for defined products and do not address these issues particularly well; more risk-based approaches would assist. The Institution of Civil Engineers' (ICE) recent Manual of Geotechnical Engineering (Burland et al., 2012) discusses some code shortcomings in relation to this and collates a vast amount of authoritative information.

Case histories have always been crucial to safe and effective ground engineering (see e.g. Charles, 2008) and go hand in hand with sound theory and calculations. A designer should have a thorough command of comparable experiences and case histories, of both successes and failures. An observational approach is always appropriate in the ground. This requires experienced personnel in close contact with the works, empowered to exercise sound engineering judgements as works proceed. This has been the essence of professional civil engineering from early history, enshrined in developed and 'well-winnowed' experience. As procedures have become increasingly commoditised and automated, there has been a tendency to subjugate this and reduce or dispense with technical site expertise, with some serious consequences.

A subset of the observational approach is the observational method (OM) (Ciria, 1999; Peck, 1969). This prescribes decisionmaking and response procedures based on monitoring, which permit economic, sometimes quite bold, construction methods, with potentially large savings in cost and time. Such should be only in the hands of experienced professionals, who can fully understand the risks and adjust to the feedback in good time. There must always be safe and practical fallback options. The success of the method is consistent with the fact that none of the cases here relate to truly $\mathrm{OM}$ projects.

\subsection{Soft and marginal soils including fills}

A large proportion of ground-related problems arise from construction on soft ground, including many types of made ground or fill. Such soils are prone to settlements, which can occur rapidly on granular soils but can continue for many years in clays, peats and some made ground. A distinction must be made with engineered fills, which are closely specified, suitably selected, placed and compacted to a specification - in effect quality assured - and for which records should be available, increasingly so nowadays. Some loose soils are prone to liquefaction or flow slides. Most historical cases in the UK have long since been identified and addressed. However, and despite all the warnings of history, there continue to be serious incidents. 
In recent years, the authors have addressed several such failures and there have been a number of major incidents worldwide.

Table 1 summarises the authors' experience of over 100 substantial soft-ground projects. Most were relatively successful but about $40 \%$ encountered significant problems. Most of these cases involved several issues as indicated. 'Major' problems include very lengthy delays, highly disproportionate costs and major litigations.

An extreme case involved very large settlements on a housing development built over a bog, with some $7 \mathrm{~m}$ of peat and very soft alluvium below. The houses were satisfactorily piled, but the infrastructure was constructed as a shallow stone platform on geogrid, with no special measures to address the very compressible ground below. As this settled, ground levels were made up, greatly increasing the loading and exacerbating the problems, particularly with the drainage. The worst settlements were approaching $3 \mathrm{~m}$ and still continuing at over $100 \mathrm{~mm} / \mathrm{year}$ in places after about 10 years. The consolidation and particularly creep-type settlements of the peat had been grossly underestimated. Despite valiant works by the developer, the roads, services and plot surrounds became unmanageable. Figure 1 shows an example of a driveway, originally flat, but eventually

Table 1. Cases showing construction problems on soft ground - overview

\begin{tabular}{lcccc|} 
& & \multicolumn{3}{c}{ Problems } \\
\cline { 3 - 5 } Topic & Total cases & Significant & Major \\
\hline Soft-ground cases & 130 & 37 & 40 & 8 \\
Settlement & 74 & 41 & 25 & 5 \\
Stability & 34 & 68 & 20 & 3 \\
Ground improvement & 32 & 44 & 11 & 3 \\
Piling & 20 & 40 & 6 & 2 \\
Shallow foundations & 54 & 28 & 13 & 2 \\
Construction & 75 & 13 & 8 & 2 \\
Programme/delays & 75 & 35 & 20 & 6
\end{tabular}

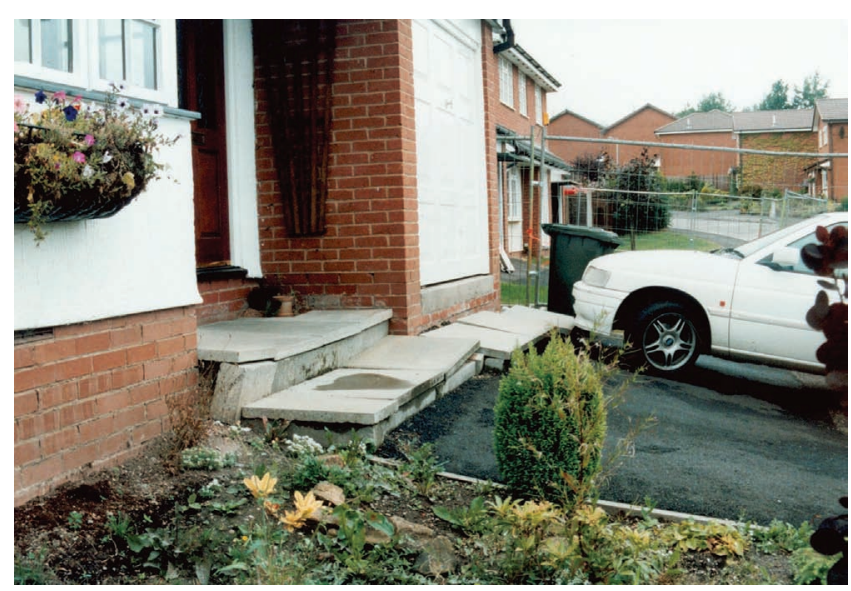

Figure 1. Housing with oversteep drive - after nearly $3 \mathrm{~m}$ settlement on peat sloping at a steep angle and falling away such that the garage could not be accessed and a step formed.

The 4-month court case included a claim of failure to employ suitable geotechnical expertise. Eventually some 40 houses were demolished and the remainder of the estate required an expensive piled road to maintain access. The authors have advised on many similar but less dramatic cases involving long-term ongoing settlements on peat and other marginal soils. Some further examples of soft-ground cases are discussed by Tonks and Antonopoulos (2015).

The lessons to be learnt are mainly the importance of involving a high level of geotechnical expertise from the outset and as works progress. Amounts and particularly rates of consolidation settlements are notoriously difficult to predict and can be very variable with varying conditions. However, many quite onerous sites have been economically developed using suitable ground improvement technologies. Predictions can be greatly improved by monitoring as work proceeds, particularly where such developments proceed over several years. Risks and uncertainties can be reduced (but not eliminated) by high-quality investigations and testing, including field trials (Tonks and Ameratunga, 2012).

\subsection{Shallow foundations and ground-bearing slabs}

Shallow foundations are normally designed to have high factors of safety against bearing capacity failure (collapse/ultimate limit state). Problems mostly relate to excessive movements and associated damage. Long experience has shown that keeping applied stresses to less than a third of codified or calculated ultimate capacity keeps settlements acceptable for routine shallow foundations to prevent cracking or distress. There are methods for more sophisticated analyses for the extensive range of foundation and ground conditions. However, there continue to be failures, attributable largely to lack of investigation, interpretation or awareness.

Figure 2 shows the wall of an old mill that collapsed when the adjacent ground was excavated without due investigation or consideration. The foundation was very shallow and varied in level. The coloured balls visible on the ground are from a nursery in the building! Staff saw cracks appearing and evacuated the children only minutes before the collapse. There was no proper involvement of geotechnical expertise in design or construction and no desk study or due investigation, which could readily have identified and prevented the serious problems here.

The authors have encountered many other cases of collapses or unacceptable movements of foundations, due to, among other things, lack of allowance for adjacent slopes or groundwater or failure to identify ground conditions correctly. Many old footings and other works were built very economically, not enjoying modern factors of safety. Some are 'on a knife edge'.

Ground-bearing floor slabs continue to give a substantial number of problem cases. Slab movements and damage can often be quite 


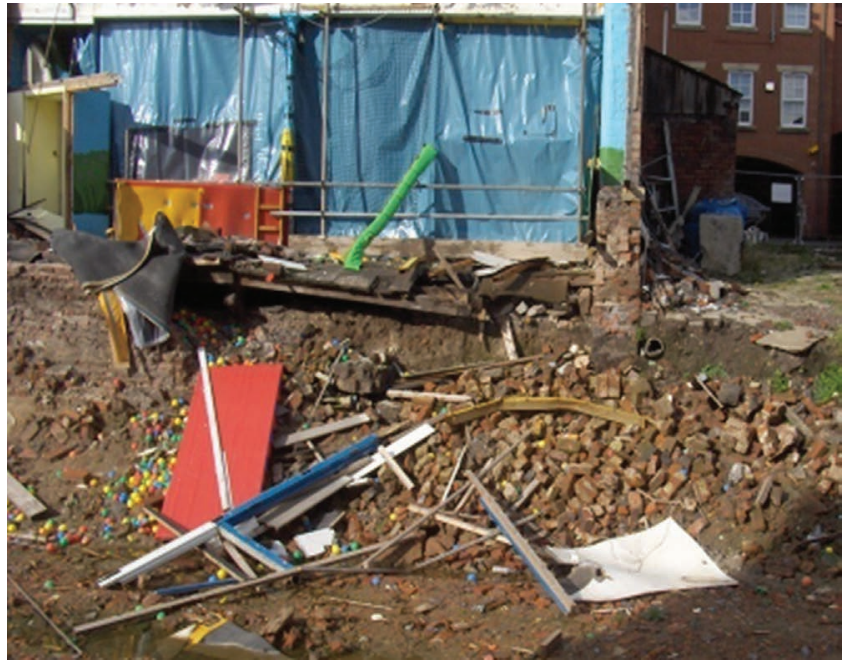

Figure 2. Collapse of wall on shallow footing

readily remedied by injection grouting methods, relevelling to tolerances of within a few millimetres. In several cases, this was not done for a long time, leading to disproportionate concerns and high costs for the affected parties. When disputes arise, there is understandable pressure for a full and final solution. However, such cases can sometimes be proactively managed for modest cost. This can also greatly mitigate problems for the time being while matters are being resolved.

There have been several recent cases of significant settlements disrupting operations in warehouses on various type of slabs, some ground-bearing and some on piles or ground improvements. A key issue can be lack of experienced site supervisory personnel validating records or identifying and investigating possible anomalous behaviour. Some pile types allow real-time 'feedback' to validate that suitable depths and capacities have been reached. There have always been occasional problems, but most are well known to piling and geotechnical specialists. A review of the authors' cases suggests that all were avoidable had available knowledge and good practice been followed.

\subsection{Landslides, slopes and stabilisation works}

The authors have long been involved in a very wide range of slope projects for road, rail and various public or private developments. The vast majority on their files have either been new works designed and constructed satisfactorily or existing, often quite old 'assets', identified as at risk by standard inspection procedures and suitably managed or remediated. However, each year, the authors encounter a number of failures, mostly requiring emergency works and some of which involve substantial inquiries, forensic investigations or legal cases.

Nettleton et al. (2010) discuss a number of examples. Space precludes detail here, but the following summarises some key points and common features.
- The engineering geology is crucial. Most soil and rock types (at least in the UK) have been studied, many in much detail, and there are numerous case studies, which should be identified in desk studies (but all too frequently are not).

- High-quality fieldwork and attention to detail are very important. Techniques such as digital terrain models have advanced greatly in recent years and allow far more attention to the three-dimensional (3D) geometry and geology.

- There continue to be many incidents due to natural or climatic conditions, notably high antecedent rainfall, where surface and groundwater drainage needed to be understood and managed better during construction.

- Slopes in clay soils and rocks, including mudrocks, can stand at steep angles in the short term but fail, sometimes dramatically, with time due to changes in pore-water pressure. This follows well-understood geotechnical principles (effective stress) but remains a mystery to most non-specialists.

- There are various other forms of soil and slope deterioration, including weathering, again increasingly being understood from careful studies, including forensic investigations.

Major generic slope failure types include Hong Kong landslides, subject to intensive studies and works since several events causing collapse of buildings and fatalities in the 1970s, and Scottish debris flows, subject to much study after several serious incidents following heavy rainfalls in 2004, notably closing the A85 Road in Glen Ogle (Winter et al., 2005). Perhaps the most challenging constructed rock slopes on the UK transport network are at Stromeferry. About $6 \mathrm{~km}$ of major rock slopes were originally blasted at steep angles for construction of the rail line to Kyle of Lochalsh along the edge of Loch Carron. They were then blasted back further in the 1950s to construct a single-track road on the landward side. This resulted in several rock slides and a major legal case against the designers, with fears of substantial further mass movements. Figure 3 shows one of the affected areas, where an avalanche shelter was constructed to protect the road and rail. Many of the rock faces exceed $30 \mathrm{~m}$ direct height, with substantial natural slopes above and ongoing debris flows as well as rock falls. The slopes have been subject to extensive studies and progressively stabilised by netting, bolts, anchors and other details over many years (Nettleton et al., 2010).

Similar issues have arisen extensively elsewhere in Scotland and other mountainous areas of the UK and have led to substantial research and development. The risks are now well known to the major stakeholders and are managed accordingly but remain problematic. Potentially expensive works have to be prioritised and balanced with other needs on a risk basis. Incidents still can and do occur and the resolution processes can be difficult. Some parties have developed extensive procedures to manage slopes and other geohazards. However, there are many other owners with lesser resources and expertise, faced with managing a limited number of slopes. Difficult cases still arise for both natural and man-made hazards, not least concerning failures of slopes with several owners and 'outside parties'. 


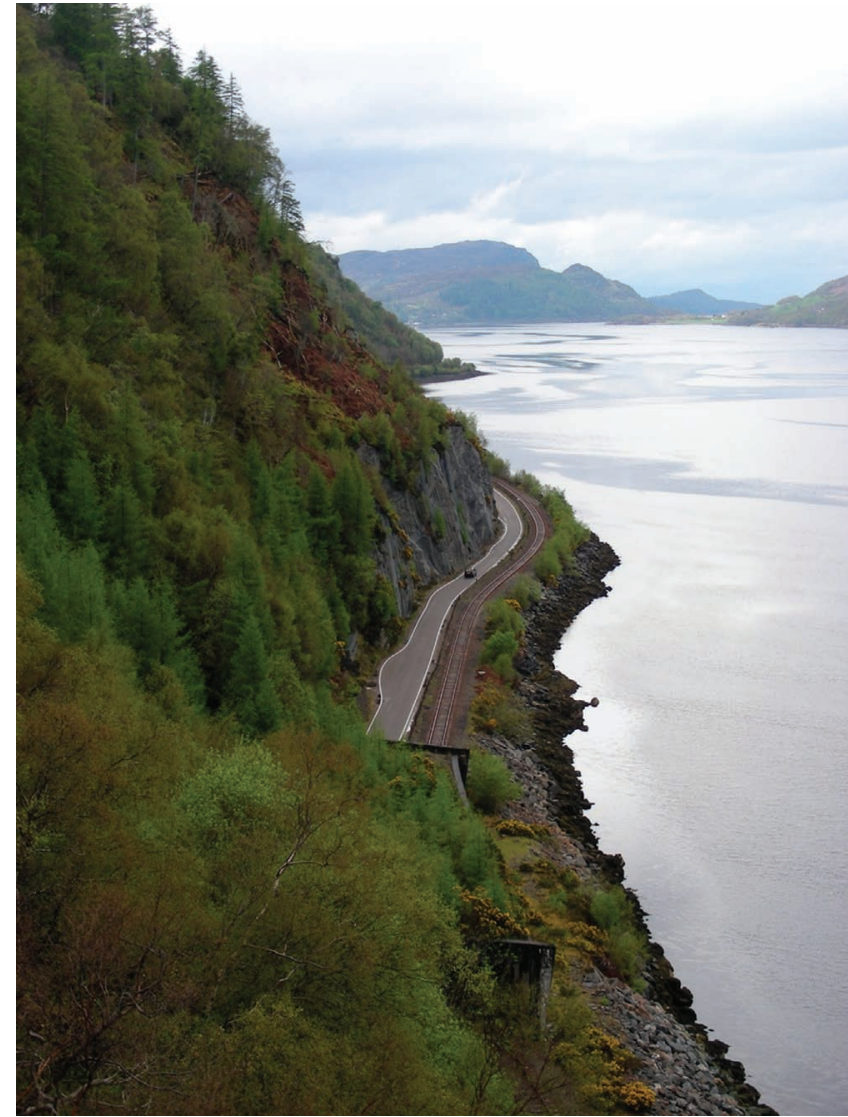

Figure 3. Steep slopes above road and rail at Stromeferry

The general lesson to be learnt is the importance of a reasonably proactive approach to slope management. The authors continue to encounter too many cases where a geotechnical inspection would have alerted the parties and should have led to suitable actions. Tonks et al. (2008) discuss this further in terms of a proportionate approach to hazard assessment. A positive example is a local authority on the UK coast with extensive roads, housing and other assets above and below cliffs. After some years of considerable ongoing problems, a proactive slope management strategy has been developed to allow timely interventions on a prioritised basis.

\subsection{Waste including geocontainment and barrier systems} Waste and landfill cases frequently include significant geotechnical issues. Some recent cases involve substantial slope stability and settlement issues, in some instances exacerbated by the phasing of developments over many years. Landfill cells are typically constructed at intervals during the lengthy life of a large facility. However, the groundwater or ground conditions may change with time, and investigations are commonly not repeated for later phases.

At a site in a former opencast coal mine, artesian groundwater conditions developed for one of the later cells, leading to uplift pressures on the liner. Figure 4 shows the side-slope and the resultant failure after the geomembrane had been removed for forensic investigations. This cell had to be redesigned to include substantial underdrainage and required a complete rebuild. Remedial costs substantially exceeded the original construction costs and delay to operations totalled about a year.

Knowledge of geosynthetic (plastic) materials has developed rapidly since the 1980s and is now a mature technology discipline, sometimes termed 'geocontainment'. Numerous problem cases in the early, 'innovative' stages of development led to extensive specifications and procedures for a high level of construction quality assurance (CQA). These are now commonplace in landfill sites, but problem cases still arise for less highly engineered and regulated facilities.

Investigations into a 1980-1990s landfill cap at a major facility in north-west England (Gallagher et al., 2016) recently revealed previously unsuspected issues. The geomembrane itself had performed well, with little evidence of degradation over approaching 30 years. However, extensive tear-type damage was uncovered, notwithstanding reported CQA of the liner welding at the time. The damage is attributed to the original construction practice, with the plant getting bogged on unduly soft cover soils and damaging the as-placed geomembrane. Figure 5 shows one location of damage exposed when cover soils were removed. The horizontal pipe is a land drain. The adjacent vertical pipe is a gas vent, with a boot detail that was found satisfactory.

\section{Some general findings and key issues}

Figure 6 gives an overview of some of the main causes of ground-related failures, expressed as percentages of the authors' cases in which the issues featured significantly. Most cases involved the interaction of several key geotechnical issues, with other issues frequently having some influence.

\subsection{Geotechnical expertise}

A large proportion of the cases involve allegations of inadequate geotechnical design and/or interpretation, albeit not all substantiated. Some $70 \%$ of the cases examined lacked the

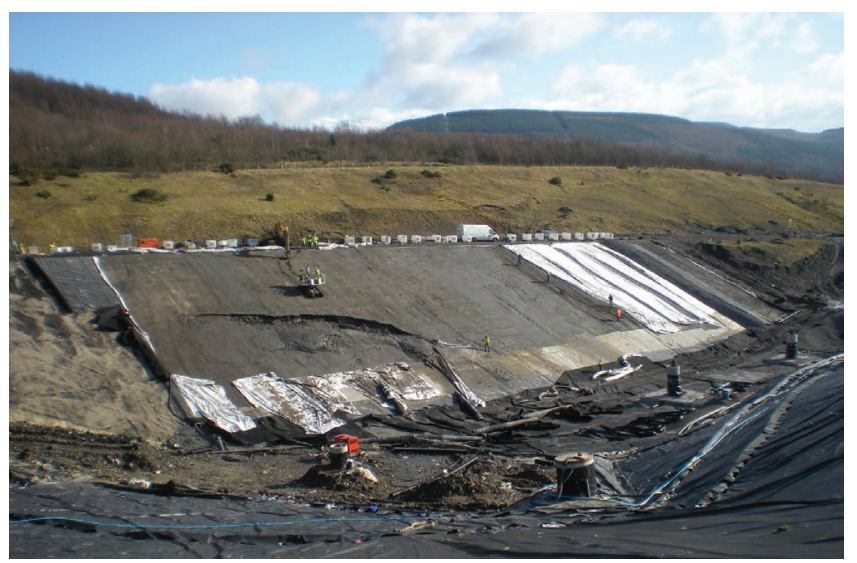

Figure 4. Failure of a landfill liner 
Grounds for concern: geotechnical issues

from some recent construction cases

Tonks, Gallagher and Nettleton

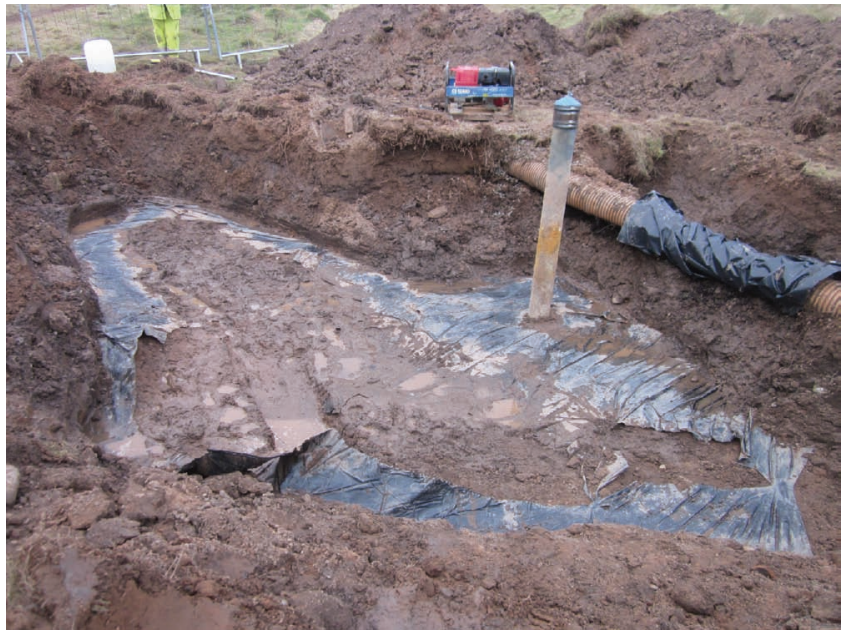

Figure 5. Damage to landfill liner associated with construction

expertise that geotechnical professionals would normally recommend for a project of comparable nature. In a few cases, experienced personnel arguably did not have the role to address the relevant issues. A few cases involved mistakes or errors of judgement that could have been eradicated by independent checking or better risk management.

Few of the causation issues might be considered genuinely unforeseeable. So-called unforeseen ground conditions have always been a significant feature of construction works. However, nowadays, most cases relate to inadequate geotechnical interpretation and advice, almost always failure to procure or apply such. Most of the problems identified would be known to experienced geotechnical practitioners and are therefore 'foreseeable'. The Register of Ground Engineering Professionals has been established by the ICE, Geological Society and Institute of Materials, Minerals and Mining to address this concern (ICE et al., 2013). This sets minimum standards of training and expertise commensurable with the geotechnical risks, now advocated in UK practice. The key issue remains whether clients will insist on using this available expertise; some of the more sophisticated organisations, particularly in the government and public sector, are requiring such for projects where geotechnical issues may be significant.

Inadequate investigation is frequently cited as a significant cause of geotechnical failures. The authors have sought to distinguish the factual investigation per se from the interpretation; their data suggest the latter is by far the greater issue. The authors were interested to note that ground investigation specialist contractors featured in less than $10 \%$ of the cases in their records. In several cases where they did, the issues were primarily matters of interpretation. That said, in many of the cases, the ground investigation was less than desirable; this simply did not feature as a main cause. There is a widespread perception among geotechnical specialists that an insufficient amount is spent on investigations, and the authors would not dispute that. For instance, piling and foundation specialists commonly complain of inadequacies in the amount and quality of information (excepting perhaps the more geotechnically advanced schemes). It appears that many projects 'manage' this risk by taking a precautionary approach. In essence, this means more conservative design and

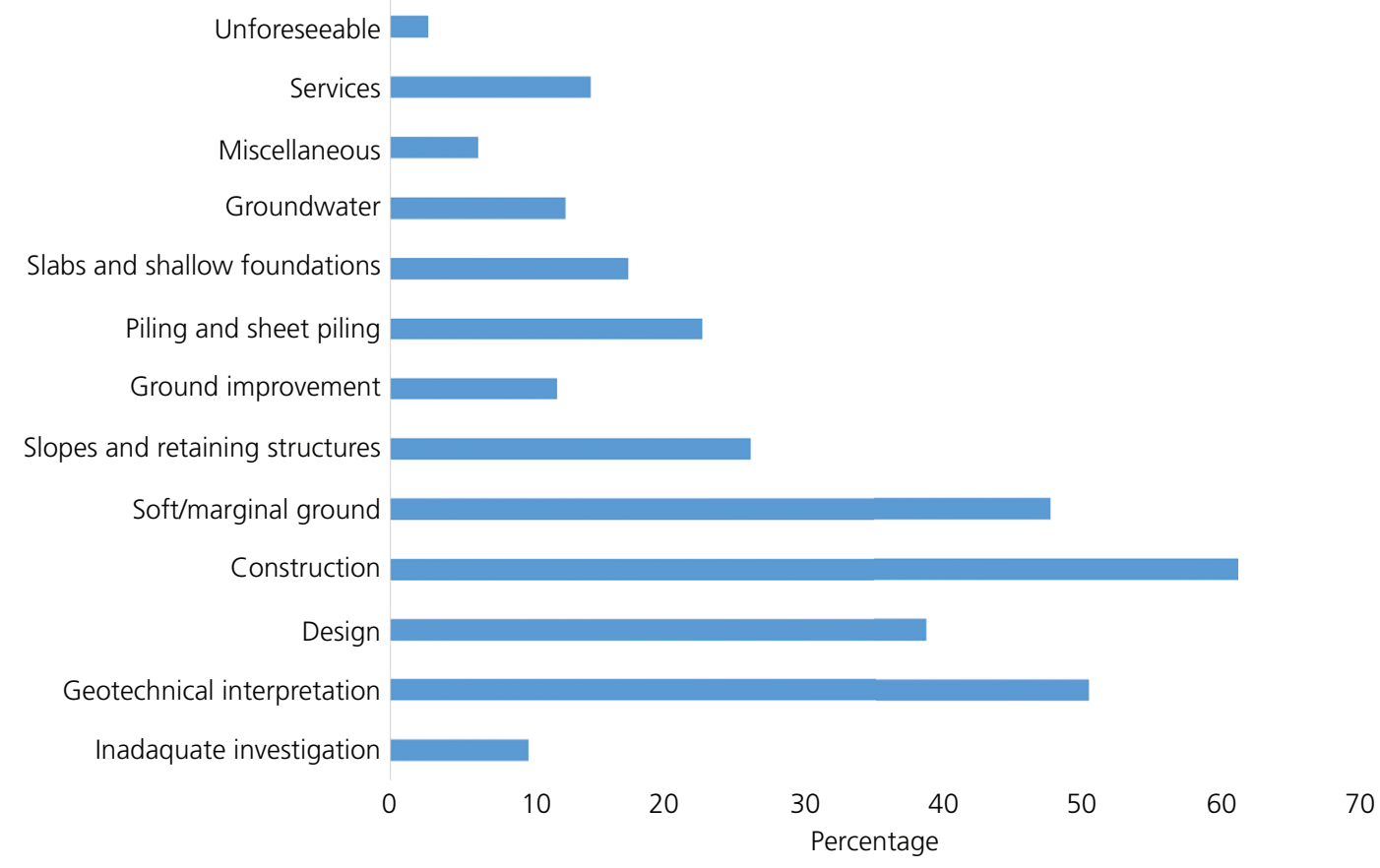

Figure 6. Main geotechnical issues (percentage identified in 110 cases) 
construction. Money spent on appropriate investigations is never wasted. The costs rarely reach $1 \%$ of project costs and are in some cases negligible. In contrast, the costs of ground-related issues commonly exceed $10 \%$, and occasionally $50 \%$, of project costs. 'Savings' are illusory, leading at best to wasted money or overcautious designs (not for this paper) but in many cases to much direct cost and delay.

\subsection{Construction issues}

About $50 \%$ of the cases include significant workmanship or other site-related issues. Many involve inadequate records or site inspections. The authors are well aware of cases where the presence of experienced site personnel would most probably have identified that the construction or ground revealed differed from expectations and significant failures could have been averted. The perceived reductions in experienced geotechnical (and indeed other civil engineering) professionals on site over recent years, at least in some places, appear of concern and a significant factor in ongoing ground-related failures.

\subsection{Existing assets, maintenance and sustainability}

An important and growing risk can be identified concerning existing assets in the ground. It is fortunate and timely that Building Information Modelling (BIM) and modern computerbased systems greatly enhance the keeping of records and the ability to use these. However, there remain extensive problems with the lack of old records. There are numerous instances of damage and delay from works encountering unexpected utilities, normally best handled by a good co-operative working with the asset owners, but occasionally warranting expert or forensic advice. Although $\mathrm{BIM}$ is a relatively recent development, geotechnical professionals have faced the challenges of managing large data sets of $3 \mathrm{D}$ topographical and subsurface data for several decades, and it is routine to develop complex ground models that evolve with projects. A significant difference between geotechnics and other engineering fields is the importance of knowledgeable interpretation of field data to develop ground models and engineering parameters that are representative and robust, notwithstanding the intrinsic variabilities and uncertainties in the ground.

\subsection{Consequential and contractual aspects}

Many cases involved major knock-on problems, particularly as geotechnical issues tend to arise at an early stage in projects. The risks can be highly disproportionate to the direct costs of the geotechnical works. The authors have encountered some major failures on turnkey and engineer-procure-construct projects where the geotechnical issues simply did not feature adequately in the overall project risk profile, at least until far too late. A good example is a major rail project that foundered on continuing settlements on soft ground, eventually being determined and re-let with major delay. Costs in dispute were several hundred million pounds. Various solutions could have been implemented for a modest cost had they been identified by appropriate investigation and expertise at an early stage. By the time that the importance of the geotechnical issues was identified, it was far too late for the scheme to be completed at anywhere near the contract period or price. The importance of adequately identifying geotechnical risks at the earliest appropriate time cannot be overstated. This has been highlighted on many occasions over the years; see, for example, Thompson (1998). Unless or until this has been done, considerable grounds for concern remain.

\section{Concluding remarks}

This paper has drawn attention to the substantial risks involved with construction in the ground, with many examples of failures and lessons to be drawn from these. Such cases continue with undue regularity. Although little in the ground is now truly unforeseeable, at least in the UK and for many developed countries, much continues to be unforeseen for a variety of reasons. This paper points to the very extensive knowledge that has been hard-won over time and the importance of obtaining timely and proportionate advice which is available.

There is a well-known aphorism that 'you pay for a ground investigation whether you have one or not'. This paper focuses on the importance of experienced interpretation thereof throughout the course of a project in the ground. The lack of such still too frequently poses exceptional risks that continue to affect construction unduly. The industry has a variable record concerning risks, from very sophisticated at the high end to patchy in places elsewhere. Many experienced client bodies have deep understandings of ground-related risks, but others do not, and too many projects continue to be seriously affected. It is hoped that this paper makes some contribution to improved understanding and practice, in a form accessible to the wide range of key professionals and decision makers.

It seems appropriate to venture some comment on the seemingly increasing number of construction failures related to the ground, contrasted with the vast increases in knowledge, such that the underlying science and expertise may be considered quite mature. Some projects have become far more complex; many of the cases cited involve complicated interactions, rather than a single overriding cause, making due resolution particularly difficult, not least for clients and advisers dragged into seemingly interminable technical detail. Few of the cases are centred on true innovation or the bolder high-level schemes, which attract commensurate levels of risk management. Most cases involve fairly routine projects, but where the complexities of the ground engineering behaviour have not been duly recognised. The authors are led to the conclusion that the overwhelming majority of issues arise from human factors rather than the ground itself. It remains disturbing to encounter cases where those working 'at the coalface' are not provided with the technical support needed.

Finally, it is of course important to maintain due proportion. The many cases cited relate to the authors' practice areas on such but remain a small sample compared to the vast number of works that address the risks in the ground with ever-increasing success in economy and safety. 


\section{Acknowledgements}

The authors gratefully acknowledge the many parties that they have been privileged to work with on the cases drawn on herein. Circumstances surrounding failures and forensic cases are often unavoidably intense and stressful. Almost invariably, those involved have been courteous and professional in seeking to resolve matters and move forward in positive ways. This has often been fundamental to mitigating loss and together engineering the best way out.

\section{REFERENCES}

Burland J, Chapman T, Skinner H and Brown M (eds) (2012) Manual of Geotechnical Engineering. Institution of Civil Engineers, London, UK.

Charles JA (2008) The engineering behaviour of fill materials: the use, misuse and disuse of case histories. Géotechnique 58(7): 541-570, https://doi.org/10.1680/geot.2008.58.7.541.

Ciria (Construction Industry Research and Information Association) (1999) Observational Method in Ground Engineering: Principles and Application. Ciria, London, UK. Report R185.

Gallagher EM, Tonks DM, Shevelan J, Belton AR and Blackmore RE (2016) Investigations of geomembrane integrity within a 25 -year old landfill capping. Geotextiles and Geomembranes 44: 770-780.

ICE (Institution of Civil Engineers), Geological Society and Institute of Materials, Minerals and Mining (IMMM) (2013) UK Register of Ground Engineering Professional. ICE, London, UK, ICE3009(4)a.

ISSMGE (International Society for Soil Mechanics and Geotechnical Engineering) TC304 (2013) Task Force 3 International State of the Art Report on Integrating Geotechnical Risk Management in
Project Risk Management: Main and Country Reports. ISSMGE, London, UK.

Nettleton IM, Tonks DM, Denney RM and Hurworth G (2010) Recent UK experiences in investigation, design and assessment and management of hard rock slopes. Proceedings of Geo2010, Calgary, AB, Canada, pp. 939-946.

Peck RB (1969) Advantages and limitations of the observational method in applied soil mechanics. Géotechnique 19(2): 171-187, https://doi. org/10.1680/geot.1969.19.2.171.

SISG (Site Investigation Steering Group) (2013) Effective Site Investigation. Thomas Telford, London, UK.

Thompson RP (1998) The value of timely hazard identification. In The Value of Geotechnics in Construction. CRC, London, UK, pp. 3-11.

Tonks DM and Ameratunga J (2012) Trial embankments to reduce geotechnical risks on poor ground. Proceedings of the 11th ANZ Conference on Geomechanics, Melbourne, Australia, pp. $1473-1478$.

Tonks DM and Antonopoulos I (2015) Construction risks on soft ground. Proceedings of the 12th ANZ Conference on Geomechanics, Wellington, New Zealand.

Tonks DM, Nettleton IM and Denney R (2008) Some developments in rock slope hazard assessments for road and rail. Proceedings of the 1st International Conference on Transportation Geotechnics, Nottingham, UK, pp. 343-348.

van Staveren M (2006) Uncertainty and Ground Conditions: a Risk Management Approach. Butterworth-Heinemann/Elsevier, Oxford, UK. Winter MG, Macgregor F and Shackman L (2005) Scottish Road Network Landslides Study. The Scottish Executive, Edinburgh, UK.

\section{How can you contribute?}

To discuss this paper, please email up to 500 words to the editor at journals@ice.org.uk. Your contribution will be forwarded to the author(s) for a reply and, if considered appropriate by the editorial board, it will be published as discussion in a future issue of the journal.

Proceedings journals rely entirely on contributions from the civil engineering profession (and allied disciplines). Information about how to submit your paper online is available at www.icevirtuallibrary.com/page/authors, where you will also find detailed author guidelines. 